\title{
Using gamification and loT-based educational tools towards energy savings - some experiences from two schools in Italy and Greece
}

\author{
Georgios Mylonas $^{1,2}\left(\right.$ C $\cdot$ Federica Paganelli $i^{3,4} \cdot$ Giovanni Cuffaro $^{4} \cdot$ Ilaria Nesi $^{5} \cdot$ Dionysis Karantzis $^{6}$
}

Received: 23 June 2020 / Accepted: 11 December 2020

(c) The Author(s), under exclusive licence to Springer-Verlag GmbH, DE part of Springer Nature 2021

\begin{abstract}
Climate change and the need for sustainable development have become part of our daily lives. In this context, it is crucial to involve the educational community to the discussion, both students and teachers; by increasing awareness about these issues and the ways school communities can contribute to energy savings, we can kick-start a change towards more sustainable practices in our societies. The Green Awareness in Action (GAIA) H2020 research project implemented an IoT-based approach in several European schools for sustainability awareness and energy efficiency, while at the same time aiming for increasing students' digital skills. By using gamification, competitions and IoT-based educational activities, GAIA engaged directly with teachers and students in order to realize energy-saving activities in their environment. We report here on the use of gamification and competition among schools in this context, and how they helped together with IoT-based lab activities to engage students and educators to participate in the project more actively. We provide details on the implementation of GAIA's intervention in specific school settings to showcase our approach. Our findings, backed up by evaluation data and answers to a survey by 30 educators in Greece and Italy, confirm that the inclusion of competition and gamification aspects can significantly increase students' engagement, especially when having groups/schools competing with each other. Moreover, IoT-based educational activities can supplement existing educational activities in interesting ways, with students evaluating positively the experience and educators reporting increased overall student engagement in their class during the intervention period, and, on average, better class performance compared to previous periods.
\end{abstract}

Keywords Internet of Things $\cdot$ Energy awareness $\cdot$ STEM education $\cdot$ Sustainability $\cdot$ Evaluation $\cdot$ Gamification

G. Mylonas and F. Paganelli contributed equally to this work and are listed alphabetically.

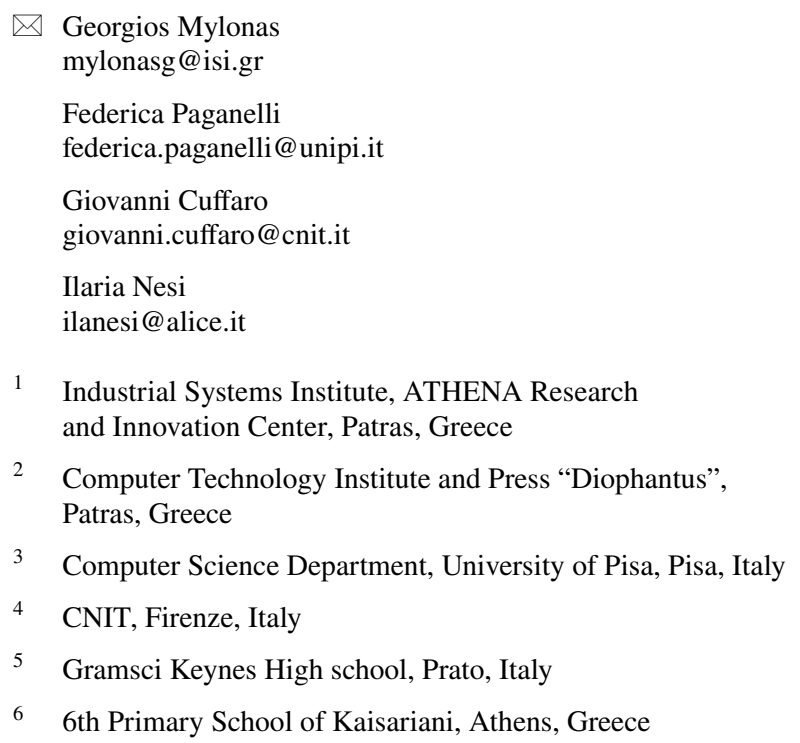


community is evident, both in terms of size and future significance. Today's students are the citizens of tomorrow, and they should have the skills to respond to challenges like the climate change. Sustainable development and energysaving behaviors are gradually becoming a part of educational programs. Indeed, in the last decade schools have been the target of studies, education initiatives, as well as energy efficiency actions in several countries. There has also been considerable interest in recent years regarding the design of educational activities for energy awareness, centered either through more conventional approaches, or structured around IoT-enabled experimentation. An example of recent activity to promote sustainability concepts in the educational sector through a structured curriculum is the United Nations' Climate Change Learning Partnership (UN:CCLearn (2020)).

In this context, the Green Awareness in Action (GAIA) EU Project produced a framework comprising IoT infrastructure in 25 school buildings, applications, as well as educational content and action plans for increasing sustainability awareness among students, while also achieving energy savings through behavioral changes in schools. GAIA was part of a group of research projects funded by the EU's H2020 framework, which focused on several groups and sectors for energy efficiency. In a broader sense, a systematic approach to promote energy efficiency and sustainability awareness can be thought of as a means through which Europe aims to meet its sustainability goals, by equipping citizens, enterprise and industry in Europe with the skills and competences needed to provide sustainable and competitive solutions to current challenges (ScienceEurope 2013).

In terms of research questions, which we were interested to investigate in our work, these would include the question "how to engage and motivate end-user groups of students to participate in energy-saving educational activities". Another one would be whether "do IoT-based and data-driven educational interventions towards sustainability awareness actually work inside the classroom". In other words, among other directions in the project, we wanted to look into the issues related to motivating a school community to use either more "soft" methods like gamification, or more technical hands-on ones, like IoT-based educational lab activities to inform students about the subject of sustainability. Such methods are in many cases easier to utilize in educational environments, compared to more brute force solutions like renovations targeting energy efficiency in a school, like e.g., improving building insulation, or replacing lighting infrastructure. This is due to the fact that such solutions can be costly to implement, while school budgets are quite strained more often than not.

Having these questions in mind, we discuss here our findings from applying gamification and competition mechanics in a high school, with the purpose of getting the students more engaged into energy-saving activities in GAIA. In this context, the original contribution of our work consists in proposing a gamification and IoT-based approach designed to be integrated into the education cycle (e.g., introducing the concept of Activity Class) with a data-driven educational methodology leveraging either a fixed sensor infrastructure or sensors offered by cheap sensory boards rather than designed as a standalone activity.

In this paper, we present the tools developed to support such an approach, including an educational toolkit, comprising IoT devices and using measurements data directly produced from school buildings. This toolkit allowed us to define educational activities within the school's computer science curriculum, leveraging IoT devices for environmental data acquisition and integration with sensor measurements. It is worth noticing that our approach consists in leveraging an Ambient Intelligence (AmI) approach to raise students' awareness on sustainability topics and motivate their behavior change, instead of deploying building automation tools. We describe the organization of the activity and related curricula and educational goals to raise students' awareness in behaviour-based sustainability. Finally, we report on the experience carried out in both directions in a high school in Italy and a primary school in Greece, and conclude by discussing the results in terms of achieved energy savings in the observation period. The activities described here were conducted in these schools during 2 consecutive school years, 2017-18 and 2018-19, with approximately 90 and 100 students in the Italian and Greek school respectively. As mentioned above, these include the application of both "soft" (gamification and competition) and "hands-on" (lab kit) mechanisms in order to engage the students and teachers.

The rest of the paper is structured as follows. Section 2 discusses related work, while in Section 3 we briefly describe the goals of the GAIA project and the real-world IoT infrastructure deployed in several school buildings and the list of tools developed within GAIA for supporting educational activities targeting behaviour-based energy savings. Section 4 discusses aspects related to gamification and competition, focusing on activities conducted in GAIA schools during school year 2017-18, while Sect. 5 discusses aspects related to the design and implementation of part of the hands-on lab activities conducted during school year 2018-19 in GAIA and how these resulted in positive learning outcomes. We continue with Sect. 6, where we describe how the increased engagement of the students led to actual energy savings through examples of activities. Section 7 provides some insights and lessons learned, while Sect. 8 concludes the paper. 


\section{Related work}

As mentioned in the introduction, we are currently witnessing a shift of the interest of the public towards issues that are related to sustainability. An example of an initiative related to teaching sustainability issues is the UN's CC:Learn program (UN:CCLearn (2020)). We have also witnessed much larger initiatives aiming to tackle climate change being announced in 2020, like EU's Green Deal plan for 2030 (EU 2020). The European Union has been consistently placing a strong focus during recent years on energy efficiency, with initiatives like Build Up (BuildUp 2020), a portal for energy efficiency in buildings. Overall, the percentage of school buildings among non-residential ones (in terms of surface area) in Europe is around 17\% (BPIE 2011). Regarding the current state of the art in inclusion of sustainability and other related aspects in the educational domain, there is a lot of activity taking place with respect to inclusion of makerspace elements in school curricula, aided by the availability of IoT hardware as well. The work in Papavlasopoulou et al. (2017) summarizes recent activity within the Maker Movement approach, presenting relevant recent findings and open issues in related research. Eriksson et al. (2018) discuss a study stemming from a large-scale national testbed in Sweden in schools related to the maker movement, along with the inclusion of maker elements into the school curriculum of Sweden. Furthermore, there is a growing number of research projects and activities that focus specifically on energy efficiency within the educational domain such as (ZEMedS 2020) and School of the Future (SotF 2020). Other recent projects like Entropy (Entropy 2020) target diverse end-user communities and do not focus specifically on the educational community.

Gamification, defined as "the use of game design elements in non-game contexts" in Deterding et al. (2011), is an approach that has been gaining popularity in the field of sustainability research. The use of gamification in education was recently discussed in Dichev and Dicheva (2017), where the need for additional systematic studies to understand the actual effect of this approach is supported bu the authors, due to most studies focusing on short-term results. In this context, Morganti et al. (2017) provide a review of recent bibliography in serious games and gamified interventions for sustainability, concluding that such approaches can foster sustainability, while there is also a wealth of different approaches and deployment strategies being tested. Regarding the use of gamification for energy saving, the work of Johnson et al. (2017) provided a recent review of the use of such techniques, while Ro et al. (2017) reports on positive outcomes of gamification on both sustainability awareness and energy savings. Zhao et al. (2017) studied the interplay between and effect of the technologies used inside building for monitoring/control, concluding that both technology advances in building equipment/devices and the ways that we interact with them can lead to energy savings. Moreover, as regards competition, the relation between competition and sustainable behavior was studied in van Horen et al. (2018), where the authors claim that utilizing competition in actions promoting sustainability is a valid "marketing" strategy, since it appeals to both groups that are less motivated and those that are more inclined to participate in such activities. This is also discussed in Wemyss et al. (2018), where both competitive and collaborative approaches are studied, and which have led to similar energy saving results. The results presented in Pietrapertosa et al. (2021) seem to verify the value of competition to a certain extent, where results from long-term energy-saving competitions among 4 schools led to modest energy savings. Our work discussed in this paper also agrees with their findings, while we also provide results on the educational dimension of the schools' participation, thus providing a more complete picture.

A number of recent projects like Charged (Papaioannou et al. 2018; Entropy 2020; GreenSoul 2020; Tribe 2020), have pursued an IoT- and game-based approach towards increasing user awareness on behavior-based energy efficiency in public buildings. However, although schools may be considered examples of public buildings, the software and hardware artefacts produced in these projects are not designed to be included in a school's curriculum. Spyropoulou et al. (2020) discussed aspects of utilizing IoT-based educational activities for increasing students' awareness and prospects of choosing a STEM-related career path. The work in Casals et al. (2019) describes results from a gamificationbased intervention for energy savings in social housing environments in the context of the EnerGAware H2020 research project. Their approach was very focused on the use of a serious game component; at the end of the experimental period this resulted in very modest energy savings. In contrast, our approach used an approach utilizing various tools and aiming to be integrated in the existing workflow of our end-user groups.

Moreover, several recent works focus on university curricula for teaching Internet of Things (IoT) leveraging a learning-by-doing and hands-on approach (Abbasy and Quesada 2017; Dobrilovic and Zeljko 2016; He et al. 2016; Zhamanov et al. 2017), while the design of IoTenabled educational scenarios in high and junior schools is less investigated. Porter et al. (2017) argue that the lack of students' engineering experiences in primary and secondary education is in part due to the fact that very few teachers have an engineering/technology background and that 
the collaboration with universities and professionals would help coping with this issue. Along this direction, Gianni et al. (2018) reported on the usage of a toolkit (Mora et al. 2017) for rapid IoT application prototyping with a group of high school students. In a related manner, Katterfeldt et al. (2018) proposed the application in schools of a plugand-play toolkit together with some suggestions for successful implementation of activities in high schools. An educational framework leveraging ubiquitous, mobile and Internet of Things technology for science learning in high schools has been proposed within the UMI-Sci-Ed project, while also investigating students' stance on IoT-enabled education activities (Glaroudis et al. 2018).

There are some recent examples of IoT-driven educational activities performed with the additional objective of increasing students' awareness of societal challenges. Tziortzioti et al. (2018) designed and experimented datadriven educational scenarios for secondary schools to raise students' awareness of water pollution. Eriksson et al. (2019) is another example of work discussing such issues from a more theoretic standpoint. However, the activities in such work are typically conceived with an approach that cannot be easily integrated into school curricula. With respect to gamification utilizing IoT in the context of sustainability, and specifically for energy and water, a recent survey on the subject is provided in Albertarelli et al. (2018). However, although there are several examples of using gamification in this context, there has been little focus so far on the benefits of such an approach inside classrooms, an aspect we discuss to a certain extent in this work.

Regarding our own previous work, certain aspects of the educational activities and their implementation and integration in the schools participating in the GAIA project are presented in Mylonas et al. (2018), while hands-on lab activities are discussed in Mylonas et al. (2019a). The design and implementation of the cloud-based aspects of the project are discussed in Amaxilatis et al. (2017), while the open source hardware aspects of the project are discussed in detail in Pocero et al. (2017). In Mylonas et al. (2019b), we presented an educational lab kit and a set of educational scenarios primarily targeting primary schools for increasing energy awareness within the GAIA project.

In this work, we provide details and practical examples about the application of our toolkit, which comprises IoT devices and utilizes the GAIA platform data APIs and the Node-RED programming environment, allowing to flexibly define educational activities. We specifically present its integration within a computer science curricula in a high school, leveraging IoT devices for environmental data acquisition by the GAIA sensing infrastructure. We describe the structure of the activity and related educational goals to raise the students' awareness in behaviour-based sustainability.

\section{GAIA objectives and timeline}

The work presented here was conducted in the context of the GAIA Project (Mylonas et al. 2018). The main objective of GAIA consisted in increasing awareness and promoting responsible behavior towards energy efficiency in educational communities. The adoption of IoT technologies in the educational buildings involved in GAIA does not aim at implementing invasive solutions or retrofitting the buildings with actuators. Instead, IoT sensors and data processing technologies are used to realize data-driven educational activities. Indeed, sensors were installed in strategic locations of the schools to help students monitor the energy consumption of their building, or specific rooms, and become aware of the impact of environmental parameters (e.g., building/room orientation) and personal behaviour into the energy consumption profile and then be able to take more informed decisions. In the framework of GAIA, this type of activity were carried out, with proper adaptation, in more than 20 schools located in Greece, Italy and Sweden of different education levels (i.e., primary to high school), while also covering different climatic conditions, cultural habits and regulatory frameworks.

In order to implement the IoT-driven flavour in the GAIA educational activities, a set of sensors have been deployed in the involved schools, thus giving rise to a real-world multi-site IoT testbed. This IoT infrastructure, hereafter referred to as the GAIA IoT Platform, currently comprises over 1200 IoT monitoring endpoints and it is made of heterogeneous hardware and software technologies, leveraging different hardware/sensor vendors, as well as open-source solutions (Pocero et al. 2017). In each school, a set of sensors have been deployed to monitor the following parameters: active power, energy, internal environmental parameters (e.g., luminosity, noise), external weather and pollution parameters. The actual deployment at each site is customized and adapted to the specific characteristics of the building (e.g., size, number of students, orientation, building plan) and, in some cases, to the availability of already available sensors. The measurements are continuously acquired by the GAIA IoT Platform which implements data processing services leveraging the Apache Storm distributed real-time computation system (Amaxilatis et al. 2017). Sensor data streams are processed and aggregates extracted in real time at different time granularity (e.g., 5-minute, hour, day, etc.). These data can be programmatically accessed through REST APIs, nonetheless a set of applications have been 
developed to facilitate students and teachers in accessing and using sensors data (Mylonas et al. 2019): (i) a Building Manager web application that allows users to visualize sensor data, and also supports participatory sensing-driven data injection and (ii) an Android GAIA Companion app offering a more basic but ubiquitous access to data.

In the framework of GAIA, a set of IoT-driven educational activities have been designed and experimented that exploit sensors data, gamification and IoT hands-on experience. Gamification-inspired activities have been centered around the GAIA Challenge, a serious game web application, while hands-on IoT activities leveraged the GAIA IoT educational lab kit, made of hardware and software technologies supporting the design of IoT classes/tutorials.

\section{Gamification and competition}

In this section, we report on our experience in supporting the use of the GAIA Challenge in three classes of the Gramsci Keynes High School in Prato, Italy. Overall, the GAIA Challenge ${ }^{1}$ is an online application aimed at students, designed to raise energy awareness and act as a playful introduction to sustainability aspects by leveraging gamification mechanics. The core of the application is a set of online Quests, grouped into five subjects related to energy consumption reduction. The Quests are offered to students as steps of a "journey", on top of a game "board" (see Fig. 1). This journey can also be enhanced with Class Activities, which are designed by teachers. For instance, Class Activities can consist in deeper investigation of some topics, energy-saving actions in the real-life, observation of monitoring data provided by the IoT platform, etc. The educational activities supported by the Challenge aim at motivating participants to engage in energy saving topics, by seeing their impact on the school facilities' energy consumption over the course of the challenge and, finally, competing against other classes and schools. Moreover, students are encouraged to share their experiences within their peer group by producing and posting audio-visual material reporting activities on a "community" area. More specifically, there is a "portfolio" area, where students can showcase some of their achievements in the Challenge, or make a short blog-like post about their energy-saving activities.

Before introducing the Challenge to the classes, we performed a set of preparatory activities, such as disseminating advertising material in school areas and classrooms, training teachers through workshops, engaging the school principal and the technical staff. We also prepared brief eye-catching material, as an example of class activity created specifically

\footnotetext{
${ }^{1}$ GAIA Challenge online, https://gaia-challenge.com
}

for that school. Then, three classes of the high school started to participate to the activities. They conducted the Challenge Quests individually, while Class Activities were performed in groups. The students played the Challenge after a short introduction about the topics. Class Activities carried out by the classes consisted in analyzing monitoring data regarding the energy consumption and environmental comfort in the school facility, spotting possible rooms for improvement, devising and realizing ways of raising awareness in their school and family communities (e.g., news in the local newspaper, posts on the school website, production of videos and presentations). We should also note at this point that student registration and participation in the Challenge was completely voluntary in GAIA, and the students who participated did not have any kind of reward in their classes, like bonus grades, etc.

The students were divided into 5 groups and, to increase engagement, students underwent an evaluation. The teacher decided to assign a mark for the activity, accounted in the students' final grade for the subject (Physics in this case). The way this was computed was based on peer evaluation, and it was also proposed by the teachers of the school: first, a grade is assigned to the group as the average of the grades given by the other groups; then a grade is assigned for each member of a group by the other members of the same group. Student's grade is the weighted average of these two evaluations (25\% personal grade and $75 \%$ group grade). Such an evaluation mechanism boosted the individual contribution to the group activity and fair cooperation among group members.

All students of the three classes took part to the competition and started to climb on the Challenge's ranking of classes from all schools participating (over 20 schools in total). They also produced some "snapshots" like animated GIFs, videos and presentations. Overall, the level of engagement due to competition achieved in the school was very high. This was a successful outcome, which, however, might be associated to some unexpected and risky effects, as we experienced in the final days of the competition. Indeed, the classes began to continuously monitor the ranking and at a certain point in time they began arguing on fairness in the Challenge score and behavior of competitors. This issue was raised when they noticed that after months of activities, another team surpassed them in the overall score. Essentially, what the students then tried to do amounted to "reverse engineering" of the way that scores were calculated in the Challenge. They basically started to monitor what the other teams were doing, and whether actions from their side had any tangible effect on their school's overall score. At some point, they minimized the set of possible cases and scenarios for the way scores are calculated. This turn of events could be summarized as an ideal for the Challenge: our end-users were more than just engaged, they were 


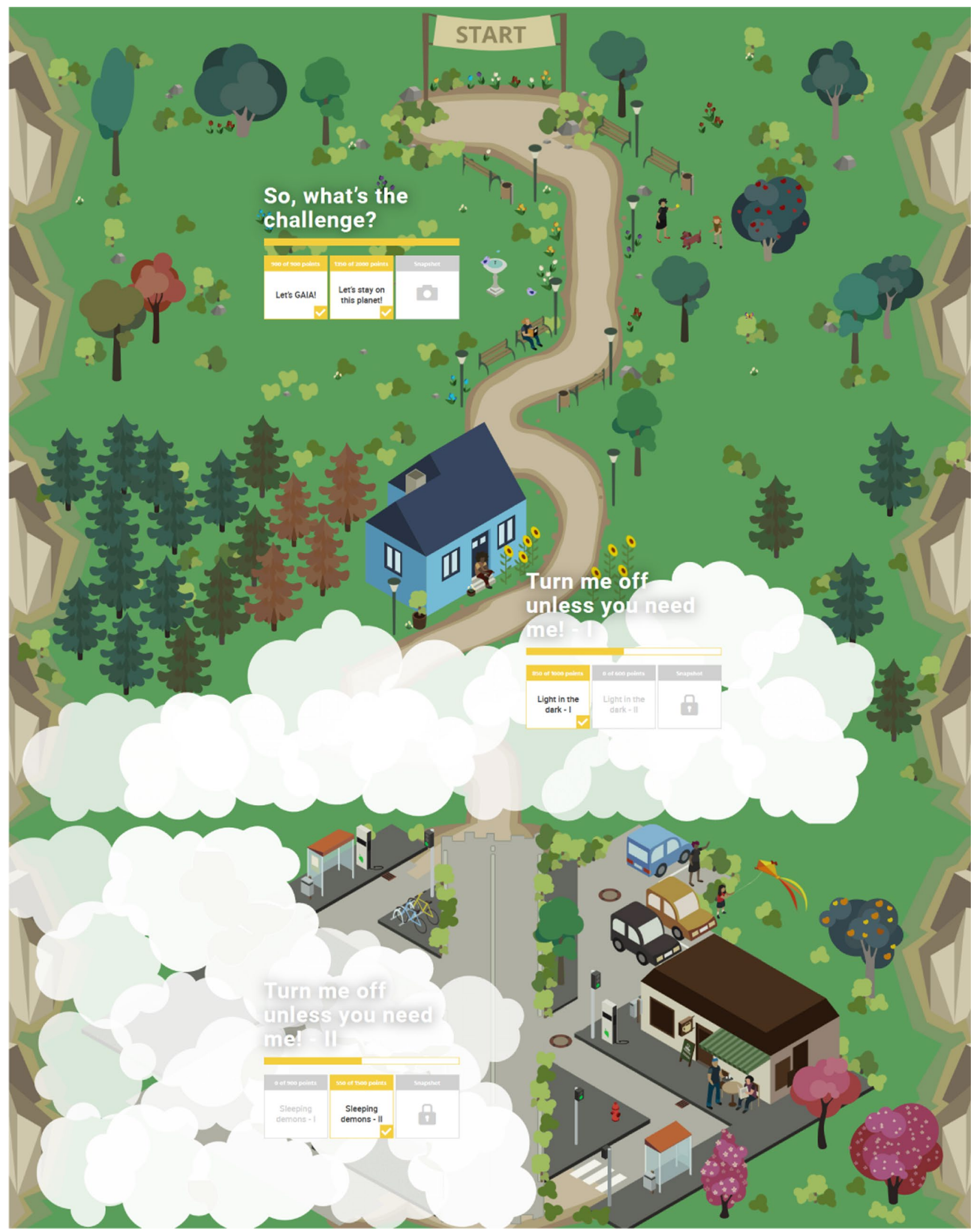

Fig. 1 Part of the "world" of the GAIA Challenge, as players complete parts of the game, additional parts in the map are revealed. In this picture, the 3 first stages are displayed, with only the first fully completed 


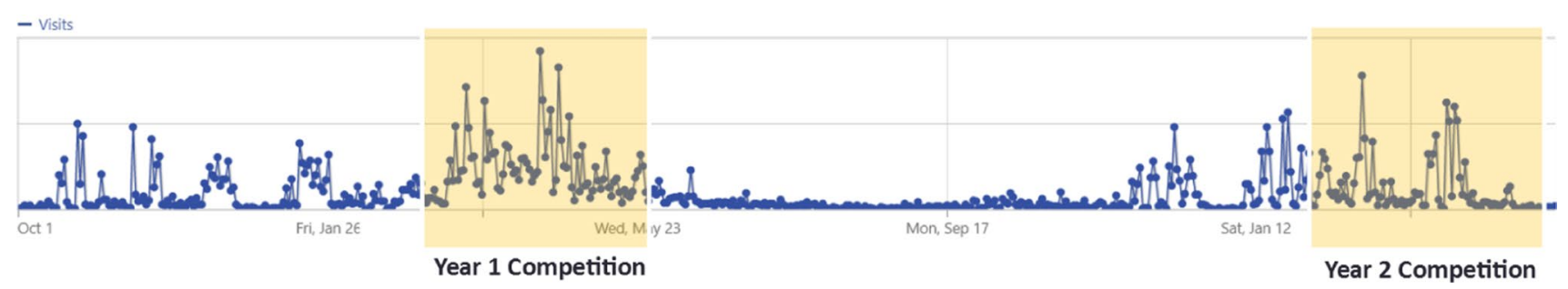

Fig. 2 A chart depiction of the total end-user visits to the Challenge, with the periods for the 2 competitions highlighted

thrilled to participate and out-compete other schools, which they hadn't even heard of before.

Another aspect was that they assumed the way the other school surpassed them in the score was a "trick", suggesting to us that the score counting method was "unethical". They noticed that 3 new users were added to a competing school a few days before the competition deadline, thus contributing extra points to the overall class score. They were very sensitive to this issue and stated that they were also ready to cancel all the project-related activities, since they perceived the process as anti-pedagogical, or even unethical. From their point of view, they were not complaining because they were no longer the best team, but against what they perceived as not fair play. The students also proposed a solution to the score "issue", as perceived by them. Essentially, the problem was that there was an assumption from the Prato students' side that new students could/should not be added to a certain school after an initial period and that all students from the other schools had registered early on. As a way to counter such complaints in the future, we setup some measures to reduce the probability of "cheating" behaviours, namely: (i) registrations are allowed only for a limited period, teachers may request an extension providing a motivation, (ii) the teacher's guide to the Challenge has been enhanced asking the teacher to control the identity of users registered to their class.

\subsection{Use of competitions in GAIA}

The GAIA consortium held two contests during the trials period of the project: the first one was held in Spring 2018 (announced on April 2018), while the second one was held in Spring 2019 (announced on March 2019). We envisioned the contests as a means to engage more actively with the schools during educational and energy-saving activities, giving some additional incentives to students, classes and schools as a whole to compete with each other. Table 1 provides an overview of the themes addressed in the 2018 competition; schools were invited to participate in all 3 categories, if possible. In both competitions, the contests were announced to schools several weeks before their public announcement, and discussed during the organizational and educational workshops that preceded these announcements on the project website. This was done to increase the anticipation from the schools' side to participate, as well as ensure that they were compatible with what the teachers and students envisioned in terms of resources and effort invested in their participation.

In Fig. 2, we are showcasing the effect of running the two GAIA contests with respect to visits to the GAIA Challenge portal during the contests period. This period also coincides with the main trial activities, so it is reasonable to expect that overall engagement would be much higher in any case. However, it is also evident that right after the announcement of the contests, there are sudden spikes in the overall activity. This, to a certain extent, verifies our own experience in terms of interaction with the schools:

- There were many inquiries by the teachers regarding the contests, even before their public announcement, since the schools had already been informed about their forthcoming announcement.

- There were additional inquiries from the schools regarding the announcement of the contests results.

- Empirically, we can say that this was an additional means to make schools in GAIA aware of each other; e.g., we had inquiries regarding the score in the Challenge during the contest from schools in different countries about their respective scores, e.g., "how is it possible that school X has a higher score than us".

- We can also say that it helped teachers give a very specific goal to their students and engage them to participate in energy saving activities.

Figure 3 provides a more detailed look at the visits to the Challenge from schools in Italy and Greece between January 8 and May 31, 2018. This figure provides some further insights as to what was described earlier in this section. More specifically, it is interesting to see how the visits from Italy progressed through time: after the sudden spike in visits from the Greek schools, there is a steady upward trend in visits from Italy, which also lasts for a long time. There is also almost no visits from Greece during the school break for the Orthodox Easter time in early April 2018, while visits 


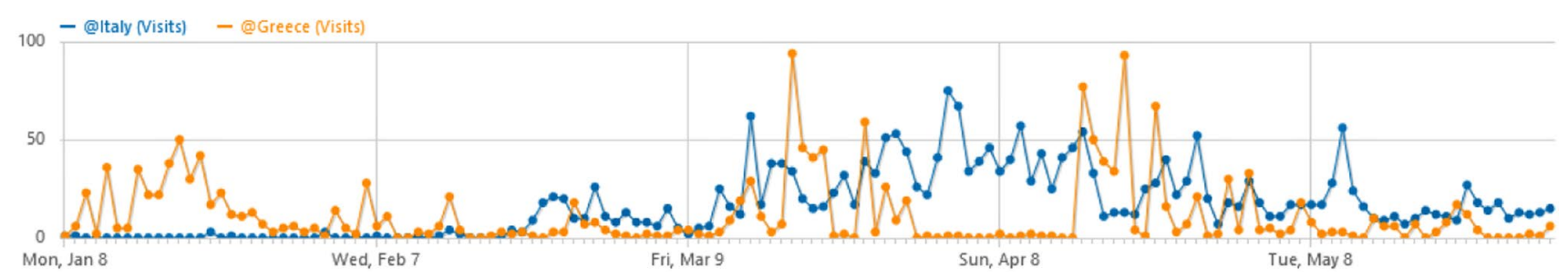

Fig. 3 A chart depicting the end-user visits to the Challenge from Italy and Greece, for the period between January 8 and May 31, 2018, during which also the first GAIA competition took place

Table 1 The themes addressed in GAIA's competition for school year 2017-18 (Year 1)

\begin{tabular}{lll}
\hline Category & Description & Participation \\
\hline Show us the improvement of your class & $\begin{array}{l}\text { School classes had to present activities already } \\
\text { done for energy reduction in their class. }\end{array}$ & 7 Submissions, 5 schools awarded \\
Share your ideas for your next school year & $\begin{array}{l}\text { School classes had to present their ideas of how } \\
\text { they will use GAIA tools in the next school } \\
\text { year }\end{array}$ & 5 Submissions, 1 school awarded
\end{tabular}

from Italy were very similar to the weeks before, although similarly there was a holiday due to the Catholic Easter a week later. After the Greek school break, there again a spike in visits from Greece, which is then followed with a new (smaller) spike in visits from Italy. It was also around that time when we started to receive the comments regarding fairness and ethical aspects from the Italian students, i.e., our statistics also back up the claims about increased engagement. In terms of more specific numbers, the average daily number of visits after the competition was announced was more than triple the average during the weeks just before the announcement.

Another interesting remark is that students did not necessarily go for the "big" prizes; e.g., in the first contest there were awards for schools like a tablet, or a Raspberry Pi sensor kit, to be handed to the winning class. In practice, we saw that students and teachers were much interested in getting recognition. After witnessing such behavior, we decided to change the type of awards for the second contest and organize the awards procedure in a more "publicized" manner, in order for the schools and the students to be able to show their achievements to their peers. Overall, we can safely say that the use of the contests as a tool to increase the engagement of the students and the teachers paid off in a very substantial manner for GAIA.

\section{Hands-on loT for a high school curricula}

The gamification approach described in the previous section had the advantage of providing a playful and generalized introduction to energy awareness topics, while also allowing teachers customizing the content by uploading custom quizzes and creating their own Activities tailored to the actual students (education grade, interests, etc.). Nonetheless, some teachers of the high school in Prato, Italy, expressed the intention of raising the bar asking for IoT-driven energy awareness activities that could be more easily integrated into their syllabus and more challenging for the students. We first describe the IoT Lab Kit and then we describe how it has been applied in the design of a hands-on IoT activity and the experience carried out in the high school in Italy.

\subsection{GAIA educational lab kit}

The LabKit consists of a sensor board, assembled using COTS devices, as detailed hereafter, a programming tool based on Node-RED, and a set of training material for teachers. The sensor board has been assembled with the following devices: a Raspberry Pi single board computer (model 3B or $3 \mathrm{~B}+$ ), an add-on board easing the connection of a set of sensors, measuring luminosity, temperature, relative humidity and noise level, to the Raspberry $\mathrm{Pi}^{2}$, including also an LCD screen, LEDs and a button. Figure 4 showcases a version of the hardware utilized in the Lab Kit activities in the GAIA schools.

The add-on board can be programmed in different languages, including NodeJS and Python. Instead of writing a programming tool from scratch, we decided to use and extend (Node-RED 2020). Node-RED is a GUI-based tool

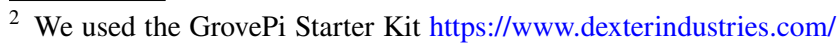
grovepi-tutorials-documentation
} 

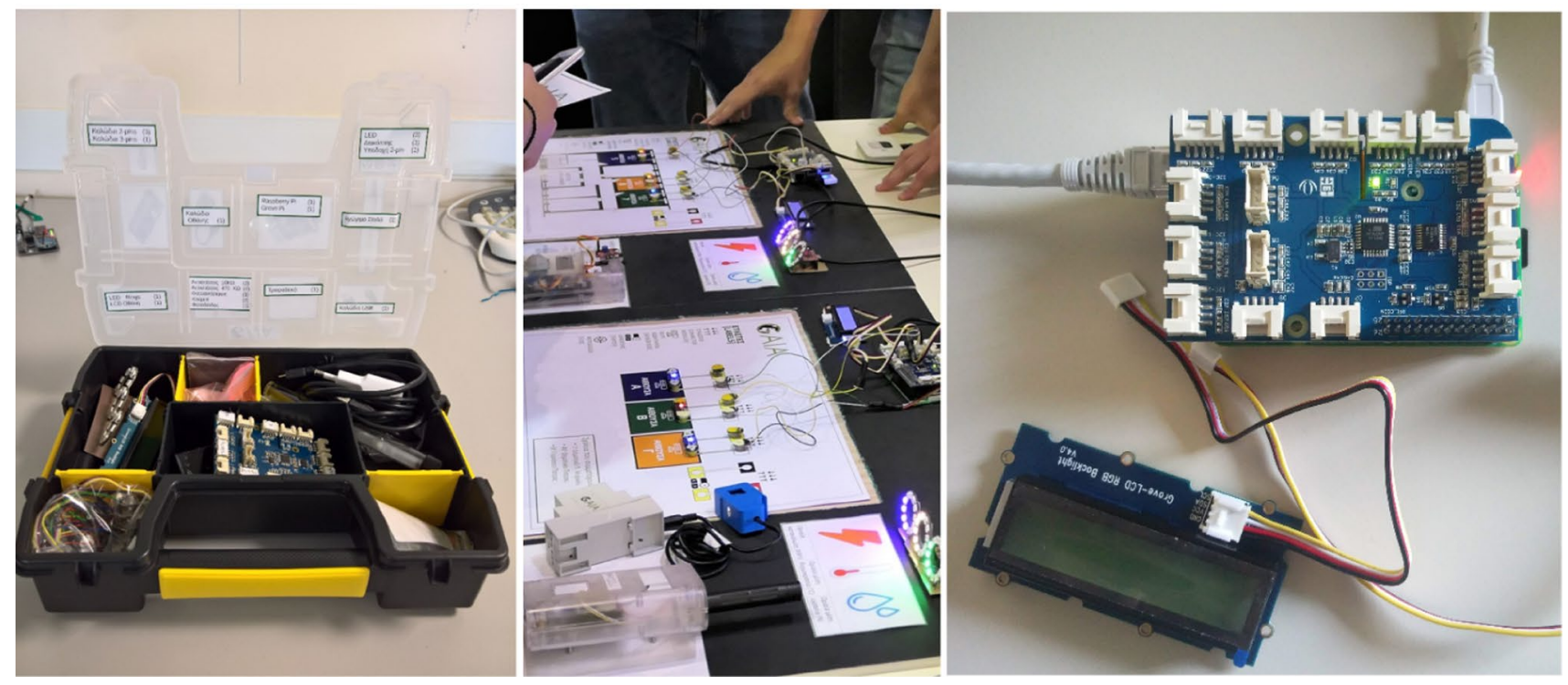

Fig. 4 Sample photos of the Raspberry Pi-based IoT hardware utilised (left, right), along with an example of an interactive installation (center) based on the same hardware, showcased in a Greek education and science exhibition

allowing users rapidly assembling and deploying an IoT application. Thanks to the adopted flow-based programming paradigm, IoT applications can be easily composed by non-technical users through the Node-RED browserbased flow editor. In Node-RED, flows consist of nodes connected by wires (Blackstock and Lea 2014). The flow editor allow users dragging and dropping node templates into a flow canvas. By adhering to the observer design pattern, each node produces events consumed by downstream nodes. For instance, input nodes may be configured to subscribe to external services, listen on a port, or managing HTTP requests. Retrieved data may be sent to downstream node instances for processing, visualization, distribution, etc. Once a flow has been created (or modified) it can be deployed and executed.

The tool provides a set of core nodes, while additional nodes created by third-parties can be retrieved from the Node-RED libraries, such as those allowing controlling and getting data from GrovePi sensors. These nodes allow easy interfacing with the sensors of the Lab Kit. By leveraging Node-RED, students can easily design flows that retrieve data from sensors, make some simple data processing and then display the obtained results.

In addition, the possibility of adding new nodes can be exploited by teachers in order to design education activities on Node-RED with various degrees of difficulty. For instance, students could implement custom data processing features or graphical widgets for displaying obtained data. Such activities could be easily adapted to the planned syllabus and training objectives decided by the teacher per class or student team. The Lab Kit allows carrying out educational activities centered around the sensor board, thus limiting required costs and easing the replicability of activities also in additional schools of the future. However, GAIA schools may benefit from additional sensor data gathered through the fixed infrastructure and stored in the GAIA IoT Platform, as described in Sect. 3.

Therefore, we developed a Node-RED plugin (called GaiaNode) allowing users to: (i) include sensors and API of the GAIA IoT Platform as data sources for Node-RED flows, (ii) inject LabKit sensors data as additional short-lived data sources. More specifically, the GaiaNode plug-in for NodeRED is a set of nodes that allows interacting with the GAIA IoT platform to retrieve measurements gathered by the fixed sensor infrastructure deployed in the schools involved in the GAIA Project, as well as pushing values of the LabKit sensors (e.g., Raspberry Pi sensors) into the platform ${ }^{3}$.

The plugin includes the following main nodes:

- LatestValue: retrieves the latest value (with some additional information) of the resource identified by the id given to the node

- Summary: retrieves the summary (latest value, averages, min, max, latest values at different granularities) of the resource identified by the id given to the node

\footnotetext{
3 The plugin has been published in the Node-RED library and is available at https://flows.nodered.org/node/node-red-contrib-gaian ode.
} 
- RealTime: connects to the WebSocket output of the GAIA IoT Platform allowing to receive real time unprocessed data as injected into the platform by the sensors

- Notification: connects to the WebSocket output of the GAIA IoT Platform to receive rule-based event notifications

- ListResources: lists the resources (sensors) associated with the given site id

- Timerange: retrieves the values in the specified time window at the specified granularity (5min, hour, day, month) for the given resource

- PushValue: pushes a value into the GAIA IoT Platform

In compliance with Node-RED guidelines each node is defined through two files: a JavaScript file specifying the behaviour of the node and an HTML file specifying how the node should appear in the Node-RED palette. Except for Notifications and PushValue nodes, each GaiaNode first registers a listener on an input event to receive messages from up-stream nodes. The received event typically contains the URI identifying the resource of the GAIA IoT Platform to be queried. The Notification node instead opens a WebSocket connection with the GAIA IoT Platform to receive rule-based notifications concerning a given GAIA monitored area (e.g. luminosity exceeded a given threshold) and produce an event with the notification message in the payload to be consumed by downstream nodes (e.g. to notify users that lights can be switched off). PushValue registers to an input event (i.e., a sensor measurement produced by a LabKit data source) and publishes the value into the GAIA IoT Platform at a given URI.

\subsection{LabKit booklet and educational material}

The LabKit is accompanied by documentation targeting the educational communities. A GAIA Lab Kit Booklet (Fig. 5) has been made publicly available ${ }^{4}$, providing a series of guidelines for Lab Kit activities. One set of material concerns the educators, identifying the educational target for each activity, the methods used, as well as a schedule for the proposed lab activity. Another set of material addresses the students part, giving specific instructions on how to perform the envisioned activities, explaining how to interconnect sensors and electronic components, etc. Difficulty levels are also indicated in the material, with more complex challenges such as coding questions and exercises available (for e.g., high school, or more advanced students). The material is also enriched with links to video guides showing the usage of Node-RED to produce basic flows leveraging the GaiaNode and some scripts providing example flows.

\footnotetext{
${ }^{4}$ http://gaia-project.eu/index.php/en/educational-material
}

\subsection{Co-design of the educational activity}

After having utilized mainly gamification and competition in school year 2017-18, for the second year (2018-19) we designed an educational activity that could fit into the syllabus of a computer science course for a class of the high school. The activity was co-designed with the computer science teacher. First, we presented a set of potential educational activities that could be designed leveraging GAIA IoT data and we discussed the possible activities with her. A second important aspect, i.e. designing the activity so that it could fit within the educational program of at least of one the subjects offered to students, was a key element to encourage teachers in devoting effort to contribute to the design and experimentation as well as in actively engaging students in proficiently taking part to the activity. The activity has been mainly designed to fit in the computer science curricula, although it can be further developed with actions carried out in the framework of additional subjects, such as sciences and physics. More specifically, the activity has been organized as a set of computer science lectures for a class of students of the fourth year of the school in Prato. In this sense, the lab kit was integrated to the class already taught in the school in Prato and became a part of the curriculum for that specific semester. The learning objectives for that course are defined at a high level by the Ministry of Education ${ }^{5}$ and then customized by each teacher. They generally consist in: learning a programming language, basics of coding, data modeling and tool for data access, manipulation and persistence, web programming. Moreover, the use of the acquired knowledge to support a study on topics in science and physics subjects is also welcomed.

In this context, the activity was designed around sustainability and energy awareness by first providing students with monitoring data gathered from the environment they live in (e.g., the school hall and the computer science laboratory), by using the sensor infrastructure deployed within the GAIA Project in a selected set of rooms and areas in the school (see Sect. 3) and a LabKit sensor board that was given to students to gather environmental parameters in some selected remaining areas. Thanks to these tools, first, the students have access to a real-world dataset, which they can learn to manipulate and query through appropriate tools in order to derive meaningful data about the school environment they live in (energy consumption, environmental comfort, etc.). Based on such findings, students, with the help of the teachers, can decide on actions for further investigation (e.g., changing their behaviour to save energy, studying the factors that influence the comfort in school environments,

\footnotetext{
$\overline{5}$ https://www.miur.gov.it/liceo-scientifico-opzione-scienze-appli cate(inItalian)
} 

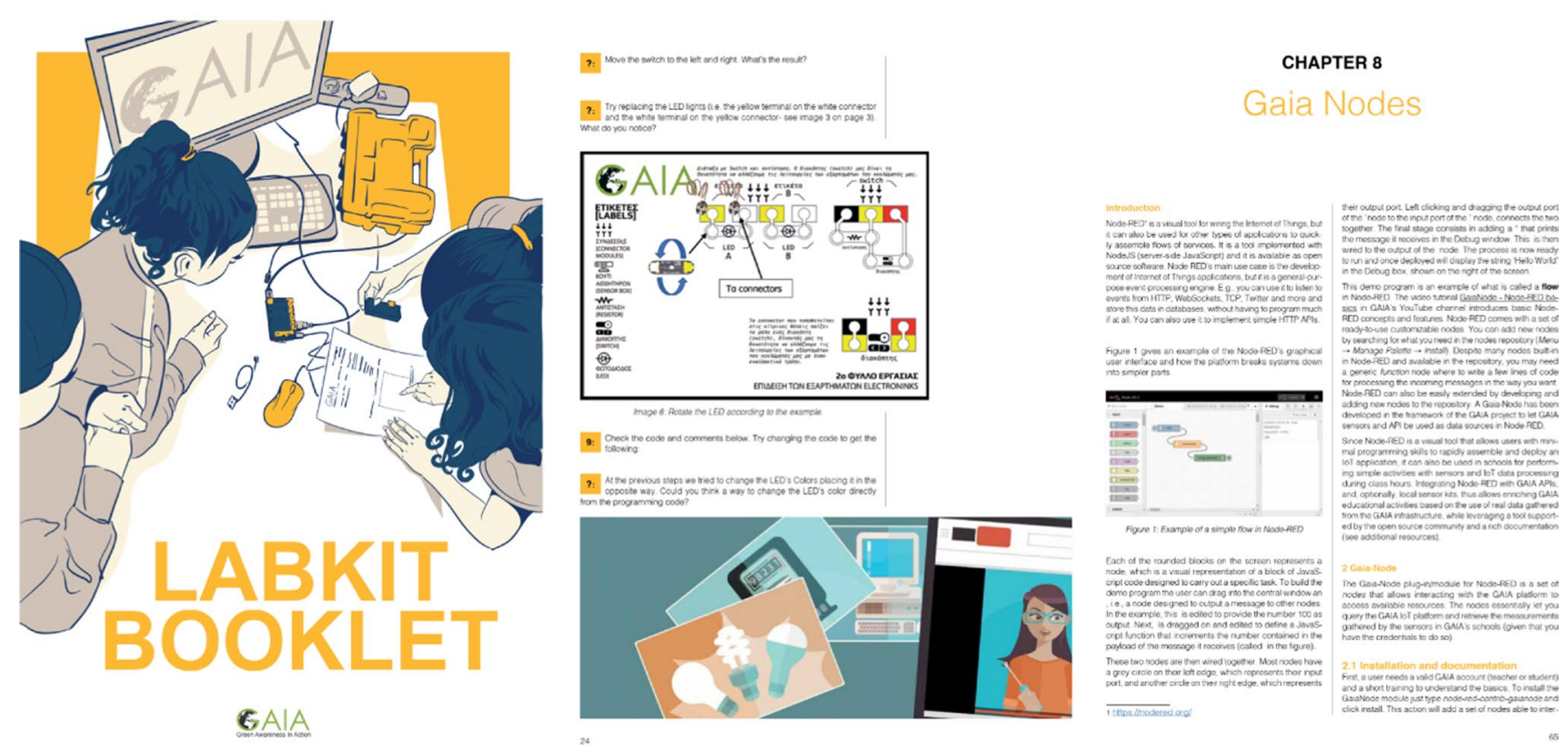

Fig. 5 The GAIA Lab Kit booklet cover and some excerpts from the included activities

etc.). Furthermore, they can enhance the experience with programming tools to develop programs for data manipulation, sharing and visualization.

\subsection{Data-driven Education for energy awareness}

Hereafter, we describe one of the IoT-enabled educational activities that took place in Prato and its integration with the existing computer science curriculum in the school. The pedagogical goals aiming at increasing students awareness on energy topics were: awareness, observation, experimentation and action. The main steps of this IoT-enabled educational activity are summarized in Table 2 . Each row of the table contains the theme for a 2-hour computer science class conducted at the school in Prato; the first 3 classes were an introduction to the technologies utilized and from then and on the difficulty and complexity of the activities increased progressively. A total of 22 high school students participated in this class, carried out weekly from February to April 2019 in a 2-hour computer science class slot. The activity has been designed by researchers with a computer networks background, with the help of the computer science professor of the high school.

Students chose to monitor the temperature of their computer science lab, since they experienced a too high and uncomfortable heat. The availability of the LabKit allowed them to monitor conditions in the lab and compare with outdoor conditions retrieved through the GAIA IoT Platform. They measured very high temperature values $\left(25-30^{\circ} \mathrm{C}\right)$ in cold days and during night, when heating was supposed to be off. They also analyzed these data while varying the room conditions (windows on/off, curtains open/closed).

Since radiators in the laboratory were not equipped with thermostatic valves, they couldn't turn their observations into direct energy saving actions (e.g., regulating radiators). As an outcome of the discussion on Day 9, they elicited a set of questions and energy-saving proposals and decided to submit them to the school principal. This resulted in a 20-minute discussion with the principal on actions for guaranteeing comfort, while achieving energy savings. The discussion was initially focused on the findings from the activity focused on the computer science laboratory and, at the end, was extended to other critical areas of the school. The discussion ended up with a set of actions to be performed by the school principal (e.g., asking interventions and funding from the local public administration) and ideas for followup activities to be performed by students (e.g., investigating the impact of actions such as shutting off computers in the laboratory after lectures and installing new textile curtains in the laboratory rooms).

\subsection{Evaluation}

We gave a questionnaire to students to assess their satisfaction and engagement in the activity. The questionnaire is shown in Table 3 and was derived taking into account similar surveys in related work (e.g., Glaroudis et al. 2018; Gianni et al. 2018). Answers were given on a Likert scale (1-5). It was submitted to students after the end of the activity. Figure 6 shows the results. Responses were 
mostly positive about the satisfaction and engagement in the activity (i.e., Q1,2,7,9 and 10). More specifically, for Q1 and Q2 (satisfied/pleased with the activity) we see an overwhelmingly positive response of over $80 \%$ from the students. Although almost $80 \%$ of the students did not find the activities "easy" (Q3), they stated that they found it "clear and understandable" (Q4) by almost $67 \%$. However, further responses related to having the knowledge to complete the lab activities and the excitement about the activity (Q6, Q8) suggest the need for improvements (e.g., distributing activities across a longer time span, additional documentation/ tutorials). Answers to Q10 and Q11 about the usefulness of the activity and the improvement in students' digital skills with a positive response by $75 \%$ and $57 \%$ respectively, reveal that the students apart from finding it interesting they also assessed it as useful and that they have learned something new from it.

Moreover, since this activity was part of the computer science education program, at the end of the activity the students took a written exam for assessment that comprised 5 free-text questions (two questions on IoT and flow-based programming concepts, two on Node-RED usage for programming applications, and one on solutions for sustainability and energy awareness in the school). Students' scores were: 2 excellent, 3 good, 6 satisfactory, 7 sufficient, 4 insufficient. On average, the class performance improved with respect to previous class exams. According to the teacher, this was probably due to the fact that previous exams aimed to verify knowledge acquired through traditional learning methodology on a larger body of content, while our IoT activity was more engaging and part of the content was produced by the students themselves. In addition, the activity was done in groups and collaboration was an incentive for students to perform better and meet deadlines, as to not damage their classmates. As a final note, the teacher also said that the activity was successful in consolidating relations among students and between class and the teacher. The students demonstrated increased engagement compared to lectures in previous months, thanks also to the awareness that their work would have had an impact on their school environment. Moreover, the teacher suggested that the time plan was too strict and the activity would benefit from additional time (e.g., $3 \mathrm{~h}$ a week instead of two) devoted to the activity. In that specific case, this would mean performing part of the activity within other teaching modules (e.g, physics or science), thus requiring the cooperation of a group of teachers and the enhancement of interdisciplinary aspects.

\subsection{Other results}

We also looked into aspects related to the concept of selfefficacy (Bandura 1997), i.e., "beliefs in one's capabilities to organize and execute the courses of action required to 
Table 3 Students' questionnaire

\begin{tabular}{ll}
\hline$\#$ & Question \\
\hline Q1 & I am satisfied with the activity \\
Q2 & I am pleased with the activity \\
Q3 & The activity was easy \\
Q4 & The process of the activity was clear and understandable \\
Q5 & I was able to follow the tasks of the activity \\
Q6 & I have the knowledge and ability to follow the tasks of the activity \\
Q7 & Attending the activity was enjoyable \\
Q8 & Attending the activity was exciting \\
Q9 & I was feeling good in the activity \\
Q10 & I found the activity useful \\
Q11 & The activity improved my capabilities in science and technologies \\
Q12 & I liked to observe and use the data and measurements \\
Q13 & I liked the lab activity with Node-RED and the Raspberry Pi \\
Q14 & I learned something new by observing and using data and measurements \\
Q15 & I learned something new in lab activities with Node-RED and Raspberry Pi \\
\hline
\end{tabular}

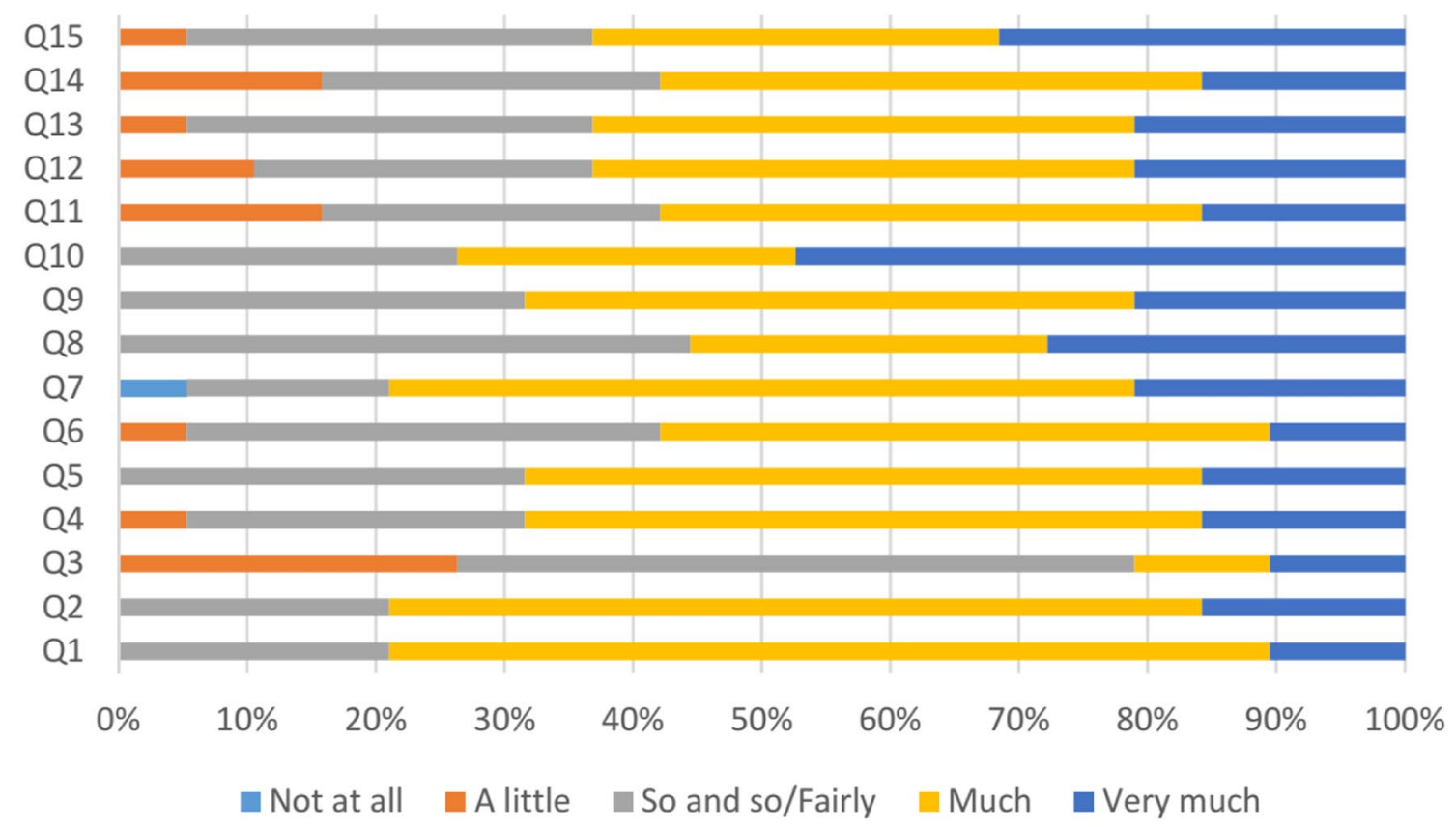

Fig. 6 Results from the students' answers to the questionnaire related to learning outcomes and their overall experience

produce given attainments". In this context, in our previous work (Mylonas et al. 2018), when surveyed about an early version of the lab kit activities applied in primary schools in Greece, 5 educators reported "positive changes in daily class activity and greater interest towards programming" and that "students who previously were indifferent, now have significant participation during lab activities". An educator specifically remarked that "low-performing students had a chance to exhibit their capabilities and receive positive comments from the rest of their class" by completing the activities successfully.

As regards Prato, we conducted an interview with the educator responsible for the course. At the beginning, she told us that she "perceived that students were cautious of the activity, since the goal seemed very ambitious". On one side, the students were flattered to be involved in a European project, on the other side they were afraid since they perceived the activity as something difficult, and not covered in books of the official curriculum. The majority of the students (apart 
from 2 students) perceived it as "a leap in the dark". However, they progressively acquired more self-confidence as far as they started to get to know the platform, understand that the activity was feasible and tackle things in small steps, but the turning point was when the work was organized in tasks and students were divided in groups (one group for each task). In addition, they were aware of the fact that their work was relevant also for the work of other groups and this fact encouraged them to do well.

As regards group composition, the students spontaneously chose their group, while some groups had more difficult tasks than others. Surprisingly, some students (low-performing students) chose the most difficult tasks. Apart from 2 or 3 students, who were disoriented till the end of the activity, the remaining students gained self-confidence and also the team spirit inside the class has improved. Except for the above mentioned 2-3 students, the others gained more confidence in their capability in carrying out the activity by themselves upon the completion of IoT Lab activity. Giving scores has also been an important factor to motivate students. Students of the first years are now making some experiments with robotics (Lego Mindstorms). Probably such students would be more self-confident in carrying out a GAIA-like activity, but this assumption cannot be checked since such kind of laboratory activities have been suspended in the school due to the ongoing COVID-19 emergency.

Moreover, apart from these aspects in Prato, we contacted the rest of the schools to query them about their experience in class. After the end of the project, we asked the questions:

- "Have you noticed any positive or negative change in students' performance and their involvement with your lesson during GAIA actions?", and

- "Have you noticed any change in your students with respect to feeling more confident in their ability to complete activities using novel technologies like the GAIA Lab kit?"

The questions were asked to 30 educators (including the one in Prato) that were directly involved in the activities of the project in their schools over long periods. Answers were given in a five-level Likert scale.

The answers to the first question were as follows: none $6.67 \%$, a little $10 \%$, so and so $36.67 \%$, big change $40 \%$, very big change $6.67 \%$. The answers to the second question were a little different but similar: none $6.67 \%$, a little $10 \%$, so and so $30 \%$, big change $46.67 \%$, very big change $6.67 \%$. Both results are clear indications that our approach had very positive results in practice, since more than half of the educators surveyed saw a big or very big change. We believe that this is a verification of the actual participation results that we saw in practice and are described in this work.

\section{Behaviour-based energy savings in Italy and Greece}

Since the common objective of the educational activities presented in previous sections is energy awareness, in this section we continue with presenting a set of activities performed by students in Prato and a primary school in Greece, targeting energy savings in schools through behaviour change. The activities showcased can be thought of as a continuation of the initial phase of awareness, that was brought forth by the participation of the students in the game, and the further elaboration in more advanced concepts through the lab kit activities. We provide brief descriptions of activities at a high school in Italy and a primary school in Greece, in order to showcase some similarities and differences between them. They can be thought of as examples of possible decisions that students can take as an effect of awareness improvement through learning, observation and experimentation steps, like the ones described in Sects. 4 and 5.

\subsection{Prato}

Leveraging measurements for their school made available by the GAIA IoT platform (Sect. 3), the three classes from Prato that participated in the school year 2017-18 decided to focus on the lighting of the main school hall as the usecase for energy savings. With respect to luminosity, there is a minimum recommended value of 150 lux for areas like indoor halls. Luminosity sensors have been installed within the GAIA Project, but given that they produce measurements that are highly related to their orientation, which is not optimal, for calculating a luminosity average value, the students had to calibrate the values they saw through the system. Making a rough estimation, students set a threshold of 400 lux for the values produced by the sensors that they thought it corresponded to "good enough" lighting. Figure 7 displays the measurements for power consumed by lights in the hall and luminosity, with the addition of the 400 lux threshold (horizontal line marked in red). Also highlighted in the figure is the interval during which luminosity in the school hall is above the threshold.

It is evident that between 10:00AM and 5:00PM lights should be turned off. This was a recurring situation in this school for months, due to its location (Italy) and orientation; i.e., it is not something that is observed for a single day or over a short time period. The next step was to act according to the plan for turning off the unnecessary lights, while also making sure not to leave any part of the hall in the dark. Lighting should be turned off for sufficient time, in order to be able to observe the change in the data. It was convenient to calculate the average values 
Fig. 7 The 7-hour period (highlighted) in which there is a potential for energy savings due to lights being on, although luminosity is above the threshold

Fig. 8 Examples of simple interventions the students made in the building
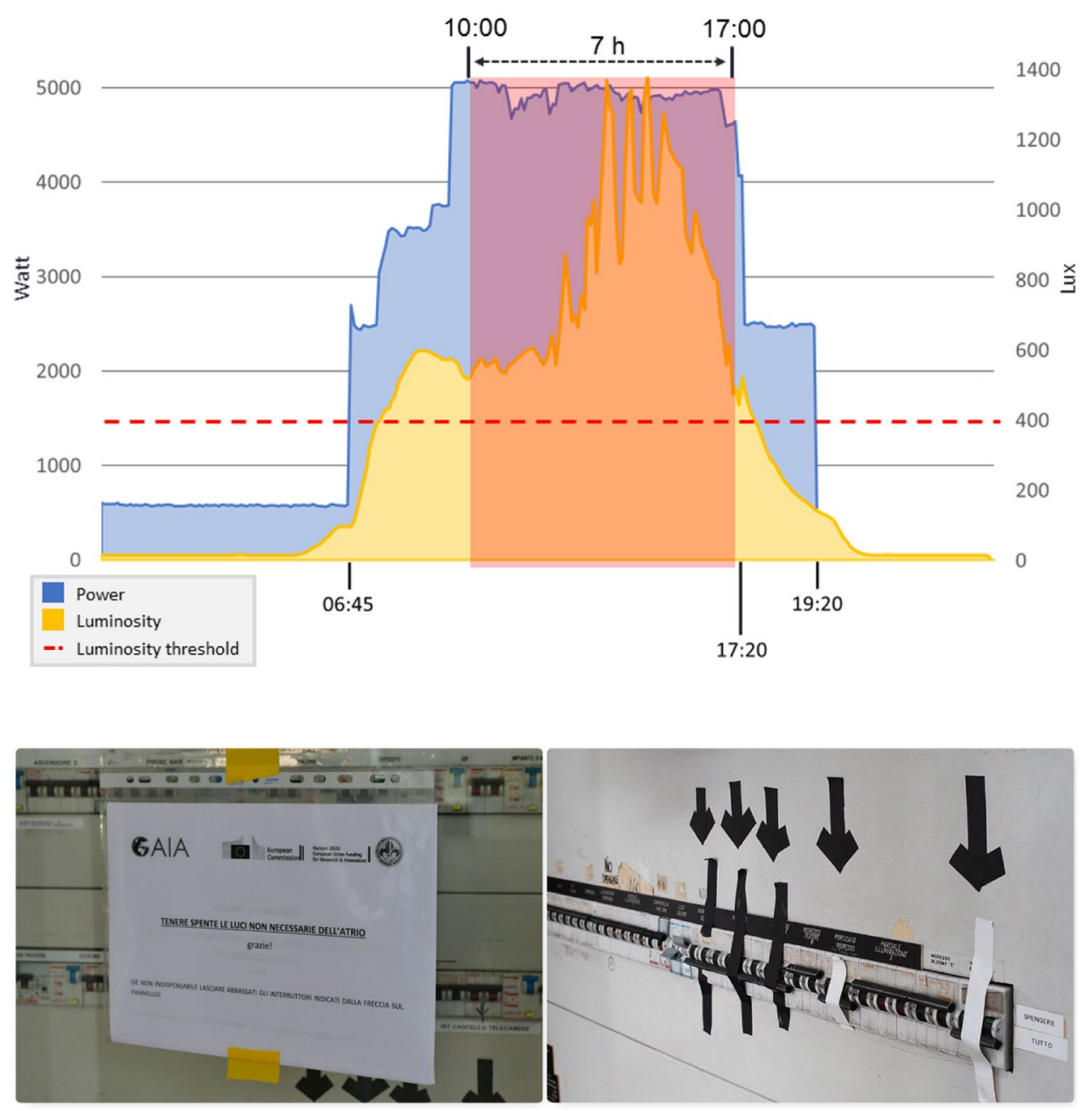

of the lighting system during a "normal" baseline period and after the intervention. The students group analyzed the new data regarding power during the period in which the light was turned off. With the lighting configured as usual, power consumption is approx. $4.9 \mathrm{~kW}$. When the students acted to keep active only what is necessary, the power consumption decreased to $1.9 \mathrm{~kW}$, thus saving $3 \mathrm{~kW}$ in the process. This means that $21 \mathrm{kWh}$ could be saved in a single day, considering the 7-hour interval during which this issue was identified. With such data in hand, students performed simple actions for raising awareness in the school staff for switching off the lights in the hall when not necessary, and involved their schoolmates in similar actions in classrooms and laboratories.

The potential energy savings analyzed in the previous steps pushed students to act. They created a set of signs (Fig. 8) to help school staff remember which switches can be turned off when natural light is enough. They also designed a poster placed in all rooms equipped with a projector: "Please shutdown the computer and the projector when not in use". Also, one of the classes involved produced a short video to encourage friends and families to join the "battle for environmental care". This video gives simple tips for saving energy and decreasing pollution. Based on achievements due to the short- and medium-term activities, the school wanted to support students in taking further measures within a longer time span, to obtain the best results in terms of energy efficiency. Students periodically observed and analyzed the impact that these changes have in the long term and monitored progress toward achieving their objectives.

\subsection{Kaisariani}

A primary school in Kaisariani, Athens, participated in GAIA. We describe their participation in this section as a counterpoint to the description of activities in Prato, which were conducted by older high-school students. The overall schedule of activities was similar to Prato: utilize the Challenge as an introduction to sustainability and energy saving concepts, complement this introduction with Lab Kit activities, and let the teachers choose a domain to focus on craft a strategy to produce energy savings. Due to the age of the 


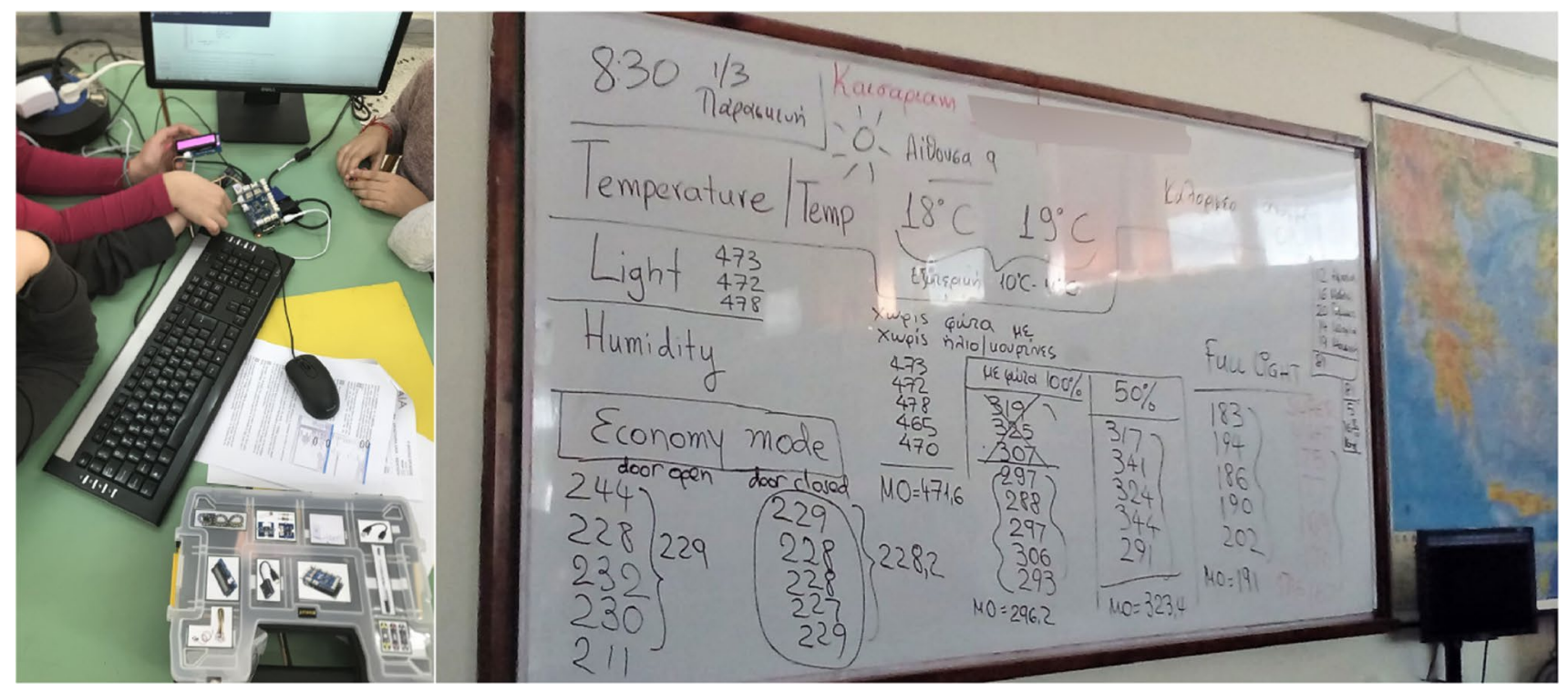

Fig. 9 Primary school students using the Lab Kit (left) and an example of in-class activities with students having completed some basic calculation on the blackboard

students involved, we held a number of additional "workshops", to help the school in their efforts to "teach" some basic sustainability concepts.

During the 2 school years in which the school participated in the project close to 100 students from the fifth and sixth grade had a direct participation in these workshops. In order to be compatible with the existing lesson plan of the school, the teachers of the school decided to integrate GAIA's activities within specific existing lesson units, following the suggestions by the consortium. In this context, the classes in which these activities were integrated were Informatics, Physics, Chemistry and Study of the Environment. The interdisciplinarity in the themes offered by GAIA facilitated this approach; e.g., the introduction to energy and electricity in Physics was combined with the study of the measurements from the IoT infrastructure in the building, while the introduction to energy sources in Chemistry was combined with a presentation of renewable energy sources and their value towards sustainability in the near future. In essence, this approach enabled the teachers to make their classes more engaging and interactive, while the students also had a first chance to use IoT technologies. It is important to note that several of the students and teachers had experience with robotics, and were aware of e.g., the Raspberry Pi platform.

The students of the school registered online and participated to the Challenge at the same time period as these workshops. Although some, mostly introductory, activities explaining the structure of the Challenge and its aims were conducted in-class, students also continued to interact with the Challenge through their devices at home. After this first period, we continued with Lab Kit activities. These were based on another set of activities than Prato, which utilized similar hardware but did not use Node-RED. Instead, it was based on more "streamlined" lab activities, that aimed to let the students understand what we measure, how it is done, and what can we do to save energy in their school. It is interesting to note that although we initially had concerns whether primary school students would complete the lab assignments, we actually had great success in this aspect. Although in many cases these in-class activities were "semi"-supervised, there were students that completed them unsupervised (see Fig. 9).

The school then continued with scheduling its own activities to save energy in the school building. First, students identified power consumption points for heating, lighting, refrigerators, microwaves, computers, printers, speakers, dishwashers, air conditioners, etc. The observations at the outset were general, concerning the entire school complex, and afterwards, more specific, and related to the part of the building monitored by GAIA. They created a school building profile and then produced a mobile measurement station. Afterwards, they appointed responsible students in order to control energy-intensive school points. With respect to the implementation of energy savings, students tried to save energy by reducing unnecessary consumption during the energy-saving week from March 18, 2019 to March 24, 2019, while as an average baseline week, the week from March 11, 2019 to March 17, 2019 was considered.

In Fig. 10, we include energy savings by hour of the day during the period mentioned above. To better understand how energy savings were achieved, we can analyse 


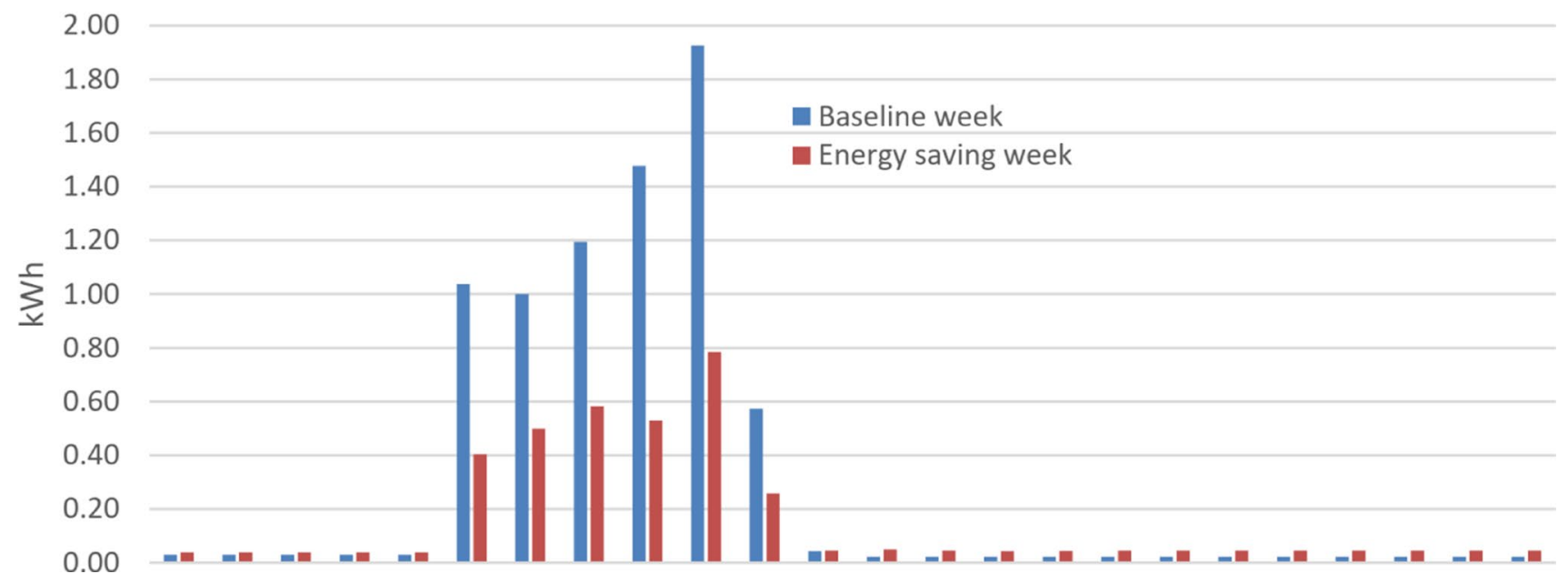

Fig. 10 Energy savings in Kaisariani by hour of the day. After the school opens and first lessons begin at 08:10, energy consumption for the part of the building that is monitored goes up significantly until 13:15. Energy consumption outside this time range is minimal

the hourly energy consumption during the energy saving period and compare it with the baseline. It is interesting to see how savings were achieved during the working hours, while during the closing hours the energy consumption in the specific part of the school monitored by GAIA was too low to have variations. We also noted that the savings were similar throughout the week. The energy savings achieved were at $54 \%$ of the energy consumption of the second floor of the school's main building. Numerically, the weekly energy savings amounted to $25.5 \mathrm{kWh}$.

\section{Lessons learned for successful interventions}

In this section, we recap some of the lessons learned through our participation in GAIA and reflected through the practical experiences included in this paper. We believe that these lessons should be seriously considered to be included as elements of a successful intervention in educational environment in the context of a research project, similar to GAIA.

Competition can help increase both awareness and engagement: as discussed in this work, the use of competition in the context of large-scale pilot activities, like the ones in GAIA, can aid in multiple aspects in a very tangible manner. Apart from the core aspect/mechanism of gamifying certain aspects and making it more interesting, competition can help to generate more long-term engagement and drive the creation of actual results. In this sense, it can help make end-users become aware that they are part of a community and make it more "personal".

Co-create tailored activities together with educators: teachers have to be involved in tailoring the proposed activities by taking into account their background and syllabus. In both examples discussed in this work (Prato and Kaisariani), the educators had a central role in adapting the guidelines and strategy of the project to their own environment and the needs and capabilities of their students. The successful application of this element in this work, via the lab kit activities, is reflected in the results of the questionnaire included in Fig. 6 and the energy saving activities.

Provide direct and informal support to educators: teachers are the gateway to students as end-users; gaining the trust and attention of teachers is the first step towards establishing a connection with students. Researchers should plan ahead for dedicating considerable resources to such activities; they are central to the overall success of initiatives like the ones described in this work, and were key to both understanding the inherent constraints and monitoring the progress of the activities. Many times, such support revealed insights that could not be captured otherwise by automated tools or analytics platforms. Moreover, we noticed early on that our end-users preferred this mode of communication with the project.

Provide short and captivating material: schools in general tend to have little time available to dedicate to extra-curricular activities. This is due to a number of facts, like the multitude of time constraints in an environment with multiple educators trying to cover a diverse curriculum. In this setting, information should be as engaging and codified as much as possible, in order to give students and educators a good understanding of what are the goals of the interventions in the school environments, which are the possibilities, and also to a certain extent their scope in terms of duration and complexity.

Competitiveness is key for engagement but has to be treated with care: in our case, a rapid increase in engagement came close to backfire. The perceived notions of the 
participating communities regarding fairness and ethical standards, especially when talking about educational communities, are important and should be taken into account when designing gamification activities and deployment strategies. This also related, to a certain extent, to the co-creation of said activities together with educators and students.

Prizes do not need to have the "wow factor": with all the talk about how competition can enhance the overall engagement of the end-user, from our practical experience we have learned that "rewards" and prizes do not have to be "flashy" or of big money value. Simple things, like a t-shirt with a project or team logo, can help students to relate to the research in question and also to realize that they are a part of a community, especially if awarded e.g., to the members of a whole class. They can also help tremendously to draw the attention of other people in the social circle of the participants, e.g., parents and friends, and promote awareness of activities conducted in school environments.

\section{Conclusions}

The successful introduction of educational activities focusing on sustainability and energy into the curricula of schools in Europe is still an open issue, although we are currently witnessing an increased interest in such aspects. In this context, we presented our experiences from our work in GAIA utilizing mechanisms such as competitions, gamification and IoT-based hands-on lab activities to increase the engagement of students. We focused here on presenting specific aspects of our activities, which we believe could be integrated into daily educational activities in schools to a varying degree, in accordance with the realities of each school.

Our results, produced during 2 consecutive school years, provide some interesting insights regarding the creative ways the aforementioned mechanisms can be used to trigger the interest of students. In essence, the inclusion of competition and gamification aspects can greatly increase the students' and educators' engagement, especially when having groups/ schools competing with each other, even in different countries. It is also important to remark that such aspects should be done in a manner that integrates to a certain degree with existing workflows in the environment of the end-user groups participating in such activities, which in our case is the school environment. Otherwise, in this environment we found out that it is hard to get the end-users interested and also keep their engagement high over longer time periods.

Regarding the lessons learned from our experiences with gamification, competitions and IoT lab activities described in this work, we could distill some general directions as follows:

- Direct and informal support to teachers: teachers are the gateway to students as end-users; gaining the trust and attention of teachers is the first step towards establishing a connection with students.

- Provide short and captivating material: schools tend to have little time available to dedicate to extra-curricular activities, information should be as engaging and codified as much as possible.

- Co-design of tailored activities: teachers have to be involved in tailoring the proposed activities by taking into account their background and syllabus.

- Competitiveness is key for engagement but has to be treated with care: in our case, a rapid increase in engagement came close to backfire.

- Prizes do not have to have the "wow factor": simple things that can help students to relate to the research in question and also to realize that they are a part of a community, can help tremendously.

As for more specific actions/interventions in order to mobilize students to participate in the context of similar research activities to the ones we conducted in GAIA, some "tips" could be the following:

- Design strategies in the medium-long term to improve energy efficiency about topics learned. For example, use notifications for alerting students to turn off some lights, based on rules that check parameters identified during previous activities.

- Increase awareness among students of the schools through interventions during classes, design of posters posted in the school halls, newsletters to be sent to families, or educational content for other classes.

- Raise awareness in the community through the creation of viral content, e.g., short videos, and share it on social networks to create further momentum.

Regarding our future work, we plan to continue supporting the existing infrastructure and expand it by adding new schools to it. We also plan to continue our work on producing educational material for use in classrooms to aid the transition towards a more sustainable future.

Acknowledgements This work has been partially supported by the "Green Awareness In Action" (GAIA) research project, funded by the European Commission and the EASME under H2020 and contract number 696029 . This document reflects only the authors' views and the EC and EASME are not responsible for any use that may be made of the information it contains. 


\section{References}

Abbasy MB, Quesada EV (2017) Predictable influence of IoT (Internet of Things) in the higher education. Int J Inf Educ Technol 7(12):914-920

Albertarelli S, Fraternali P, Herrera S, Melenhorst M, Novak J, Pasini C, Rizzoli AE, Rottondi C (2018) A survey on the design of gamified systems for energy and water sustainability. Games 9(3):38

Amaxilatis D, Akrivopoulos O, Mylonas G, Chatzigiannakis I (2017) An IoT-based solution for monitoring a fleet of educational buildings focusing on energy efficiency. Sensors 17(10):2296

Bandura A (1997) W H Freeman Times Books. Henry Holt and Co, NY

Blackstock M, Lea R (2014) Toward a distributed data flow platform for the web of things (distributed node-red). In Proceedings of the 5th International Workshop on Web of Things, WoT-14 Association for Computing Machinery NY pp 34-39

BPIE (2011) Europe's buildings under the microscope: A country-bycountry review of the energy performance of buildings. Technical report, Buildings Performance Institute Europe (BPIE). ISBN 9789491143014

BuildUp (2020) European Web Portal for energy efficiency in buildings, http://www.buildup.eu. Accessed 3 Dec 2020

Casals M, Gangolells M, Macarulla M, Forcada N, Fuertes A, Jones $\mathrm{R}$ (2019) Assessing the effectiveness of gamification in reducing domestic energy consumption: lessons learned from the energaware project. Energy and Buildings 210:109753

Deterding S, Dixon D, Khaled R, Nacke L (2011) From game design elements to gamefulness: defining gamification. In: Proceedings of the 15th International Academic MindTrek Conference: envisioning future media environments (MindTrek '11). Association for Computing Machinery, New York, NY, USA, 9-15

Dichev C, Dicheva D (2017) Gamifying education: what is known, what is believed and what remains uncertain a critical review. Int J Educ Technol Higher Educ 14(1):9

Dobrilovic D, Zeljko S (2016) Design of open-source platform for introducing internet of things in university curricula. In IEEE 11th International Symposium on Applied Computational Intelligence and Informatics (SACI), pp 273-276

Entropy (2020). Entropy H2020 Project, http://www.mdpi.com/14248220/17/9/2054. Accessed 3 Dec 2020

Eriksson E, Heath C, Ljungstrand P, Parnes P (2018) Makerspace in school - considerations from a large-scale national testbed. Int $\mathrm{J}$ Child-Computer Int 16:9-15

Eriksson E, Iversen OS, Baykal GE, Van Mechelen M, Smith R, Wagner ML, Fog BV, Klokmose C, Cumbo B, Hjorth A, Musaeus LH, Petersen MG, Bouvin NO (2019) Widening the scope of fablearn research: Integrating computational thinking, design and making. In Proceedings of the FabLearn Europe 2019 Conference ACM, NY pp 15:1-15:9

EU (2020). A European Green Deal, https://ec.europa.eu/info/strategy/ priorities-2019-2024/european-green-deal. Accessed 3 Dec 2020

Gianni F, Mora S, Divitini M (2018) Rapid prototyping Internet of Things applications for augmented objects the tiles toolkit approach. in European conference on ambient intelligence. Springer, Cham, pp 204-220

Glaroudis D, Iossifides A, Spyropoulou N, Zaharakis ID (2018) Investigating secondary students' stance on IoT driven educational activities. In: Kameas A, Stathis K (eds) Ambient intelligence. Springer Int Pub, Cham, pp 188-203

GreenSoul (2020) Persuasive Eco-awareness for User Engagement through Networked Data Devices,http://www.greensoul-h2020 .eu/ Accessed 3 Dec 2020

He J, Lo Dan Chia-Tien, Xie Y, Lartigue J (2016) Integrating internet of things (IoT) into stem undergraduate education: Case study of a modern technology infused courseware for embedded system course. In 2016 IEEE Frontiers in Education Conference (FIE), pp 1-9

Johnson D, Horton E, Mulcahy R, Foth M (2017) Gamification and serious games within the domain of domestic energy consumption: a systematic review. Renew Sustain Energy Rev 73:249-264

Katterfeldt E-S, Cukurova M, Spikol D, Cuartielles D (2018) Physical computing with plug-and-play toolkits: key recommendations for collaborative learning implementations. Int J Child-computer interaction 17:72-82

Mora S, Gianni F, Divitini M (2017) Tiles: a card-based ideation toolkit for the internet of things. In Proc. of the 2017 Conf. on Designing Interactive Systems, pp 587-598 ACM

Morganti L, Pallavicini F, Cadel E, Candelieri A, Archetti F, Mantovani F (2017) Gaming for earth: serious games and gamification to engage consumers in pro-environmental behaviours for energy efficiency. Energy Res Soc Sci 29:95-102

Mylonas G, Amaxilatis D, Chatzigiannakis I, Anagnostopoulos A, Paganelli F (2018) Enabling sustainability and energy awareness in schools based on iot and real-world data. IEEE Pervasive Comput 17(4):53-63

Mylonas G, Amaxilatis D, Pocero L, Markelis I, Hofstaetter J, Koulouris P (2019a) An educational IoT lab kit and tools for energy awareness in European schools. Int J Child-Computer Int 20:43-53

Mylonas G, Amaxilatis D, Pocero L, Markelis I, Hofstaetter J, Koulouris P (2019b) An educational iot lab kit and tools for energy awareness in European schools. Int J Child-Computer Int 20:43-53

Mylonas G, Amaxilatis D, Tsampas S, Pocero L, Gunneriusson J (2019) A Methodology for Saving Energy in Educational Buildings Using an IoT Infrastructure. 2019 10th International Conference on Information. Intelligence, Systems and Applications (IISA), pp 1-7

Node-RED (2020). Low-code programming for event-driven applications https://github.com/node-red/node-red.git cd node-red. Accessed 3 Dec 2020

Papaioannou T, Dimitriou N, Vasilakis K, Schoofs A, Nikiforakis M, Pursche F, Deliyski N, Taha A, Kotsopoulos D, Bardaki C et al (2018) An IoT-based gamified approach for reducing occupants' energy wastage in public buildings. Sensors 18(2):537

Papavlasopoulou S, Giannakos MN, Jaccheri L (2017) Empirical studies on the maker movement, a promising approach to learning: a literature review. Entertain Comput 18:57-78

Pietrapertosa F, Tancredi M, Salvia M, Proto M, Pepe A, Giordano M, Afflitto N, Sarricchio G, Di Leo S, Cosmi C (2021) An educational awareness program to reduce energy consumption in schools. J Clean Prod 278:123949

Pocero L, Amaxilatis D, Mylonas G, Chatzigiannakis I (2017) Open source iot meter devices for smart and energy-efficient school buildings. HardwareX 1:54-67

Porter JR, Morgan JA, Johnson M (2017) Building automation and IoT as a platform for introducing STEM education in K-12. Conference and Exposition, ASEE Ann

Ro M, Brauer M, Kuntz K, Shukla R, Bensch I (2017) Making cool choices for sustainability: Testing the effectiveness of a gamebased approach to promoting pro-environmental behaviors. $\mathrm{J}$ Environ Psychol 53:20-30

ScienceEurope (2013) Science Europe Roadmap, https://www.scien ceeurope.org.availableonline

SotF (2020). Towards Zero Emission with High Performance Indoor Environment, http://school-of-the-future.eu. Accessed 3 December 2020

Spyropoulou N, Glaroudis D, Iossifides A, Zaharakis ID (2020) Fostering secondary students' stem career awareness through iot hands-on educational activities: experiences and lessons learned. IEEE Commun Mag 58(2):86-92 
Tribe (2020) TRaIning Behaviours towards Energy efficiency: Play it! http://tribe-h2020.eu. Accessed 3 Dec 2020

Tziortzioti C, Andreetti G, Rodinò L, Mavrommati I, Vitaletti A, Chatzigiannakis I (2018) Raising awareness for water pollution based on game activities using internet of things: In European conference on ambient intelligence. Springer, Cham

UN:CCLearn (2020) The One UN Climate Change Learning Partnership (UN CC:Learn). https://unccelearn.org/ Accessed 3 Dec 2020

van Horen F, van der Wal A, Grinstein A (2018) Green, greener, greenest: can competition increase sustainable behavior? J Environ Psychol 59:16-25

Wemyss D, Castri R, Cellina F, De Luca V, Lobsiger E, CarabiasHutter V (2018) Examining community-level collaborative vs. competitive approaches to enhance household electricity-saving behavior. Energy Eff 11:1-19

ZEMedS . Zero Energy MEDiterranean Schools, http://www.zemed s.eu Accessed 3 Dec 2020

Zhamanov A, Sakhiyeva Z, Suliyev R, Kaldykulova Z (2017) IoT smart campus review and implementation of IoT applications into education process of university. In 13th International Conference on Electronics, Computer and Computation (ICECCO)

Zhao D, McCoy A, Du J, Agee P (2017) Interaction effects of building technology and resident behavior on energy consumption in residential buildings. Energy and Buildings 134:223-233

Publisher's Note Springer Nature remains neutral with regard to jurisdictional claims in published maps and institutional affiliations. 